\title{
Bilingüismo e identidad juvenil: aportes etnográficos para la enseñanza del quechua en secundarias urbanas
}

\section{Frances Kvietok}

Facultad de Educación, Universidad Peruana Cayetano Heredia https://orcid.org/0000-0001-6064-755X frances.kvietok@upch.pe

Recibido: $16 / 01 / 2021$

Aprobado: 26/05/2021 


\title{
Bilingüismo e identidad juvenil: aportes etnográficos para la enseñanza del quechua en secundarias urbanas y para una EIB urbana
}

\begin{abstract}
Resumen
A pesar de la larga trayectoria de la educación intercultural bilingüe (EIB) en la región andina, contamos con pocas investigaciones sobre las prácticas y los significados de la enseñanza de lenguas originarias en el nivel secundario y en contextos urbanos. Este artículo plantea la necesidad de reconocer el fenómeno del bilingüismo más allá del dominio de dos lenguas, interesándose también por las prácticas y los significados del bilingüismo para los jóvenes, la relación que guarda con sus identidades, y las consecuencias simbólicas y materiales que tiene para los individuos. Basándome en datos de una etnografía de veinte meses realizada en Cusco, Perú, esta investigación revela la diversidad y la complejidad de los repertorios comunicativos y las trayectorias lingüísticas juveniles; las representaciones negativas y positivas sobre los hablantes y no hablantes de quechua que los jóvenes enfrentan, construyen y transforman; $y$, finalmente, sus críticas y demandas para la enseñanza del quechua. El estudio concluye ofreciendo implicancias educativas para la construcción de la enseñanza de lenguas originarias en contextos urbanos.

Palabras clave: Bilingüismo como práctica social, identidad, juventud, educación intercultural bilingüe urbana, quechua
\end{abstract}

\section{Youth Bilingualism and Identity: Ethnographic Insights for Quechua Education in Urban High Schools and Urban EIB}

\begin{abstract}
Despite the long trajectory of intercultural bilingual education (EIB) in the Andes, few studies shed light on the practices and meanings of the teaching of Indigenous languages at the secondary level and in urban contexts. This article approaches bilingualism beyond competence in two languages, paying attention to the meanings and practices of youth bilingualism, its relationship to youth identity, and the symbolic and material consequences it carries for individuals. Drawing on data of a 20-month long ethnography carried out in Cusco, Peru, the study sheds light on the diversity and complexity of youth communicative repertoires and language trajectories; negative and positive representations of Indigenous language speakerhood youth face, construct and transform; and, lastly, youth critiques and demands for Quechua education. As a conclusion, the article discusses implications for the construction of Indigenous language education in urban contexts.
\end{abstract}

Keywords: Bilingualism as a social practice, identity, youth, urban intercultural bilingual education, Quechua 


\section{Introducción}

A nivel latinoamericano, la educación intercultural bilingüe (EIB) se ha impartido predominantemente en el nivel primario y en escuelas rurales, teniendo como público objetivo estudiantes con una lengua originaria o indígena como primera lengua. En la región andina, diversos estudios etnográficos y participativos han dado cuenta de las potencialidades y retos de este proyecto educativo (Hornberger, 1988; Mamani, 2019), que busca incorporar las epistemologías y las lenguas originarias en la educación escolar para los pueblos indígenas, transformando su carácter monocultural y monolingüe. En su larga trayectoria; sin embargo, la EIB no ha considerado las diversas manifestaciones del multilingüismo indígena (López y Küper, 1999), dejando fuera a niños y jóvenes que estudian en contextos urbanos, en el nivel secundaria, y quienes no tienen una lengua originaria como primera lengua. Ello también se ve reflejado en la escasez de estudios en este contexto (para excepciones ver Sichra, 2006; Zavala et al., 2014).

Desde la década pasada, algunas políticas lingüísticas regionales han creado oportunidades para la enseñanza de lenguas originarias en contextos urbanos del Perú. En la región del Cusco, por ejemplo, una normativa regional promulgada en el 2007 ha posibilitado la enseñanza del quechua en el nivel de secundaria como una asignatura de la malla curricular ${ }^{1}$. A nivel nacional, en el 2018, el Ministerio de Educación promulgó los lineamientos de los Modelos de Servicio Educativo Intercultural Bilingüe, entre los cuales figura el modelo de EIB en ámbitos urbanos. El desarrollo de estas políticas lingüísticas trae una muy esperada expansión de la población beneficiaria de la EIB, y nuevos retos y oportunidades para los docentes hacedores de la EIB (Unamuno, 2015), quienes dan forma a estas propuestas a través de sus prácticas educativas. En este panorama, resulta necesario para los educadores del nivel secundario urbano conocer cómo los jóvenes viven su bilingüismo y las orientaciones que tienen hacia sus lenguas originarias y hacia su aprendizaje - una temática poco estudiada.

Frente a ello, mediante la presente investigación, planteo la necesidad de una mirada sociolingüística crítica y etnográfica para aproximarnos al bilingüismo e identidad de los jóvenes estudiantes de quechua en secundarias urbanas. Este acercamiento nos permitirá comprender el fenómeno del bilingüismo más allá del dominio de una lengua en particular, interesándose también por las prácticas y los significados del bilingüismo para los jóvenes, la relación que guarda con sus identidades, y sus consecuencias simbólicas y materiales. Específicamente, los hallazgos etnográficos presentados dan cuenta de la diversidad y complejidad de los repertorios comunicativos y de las trayectorias lingüísticas juveniles; las representaciones negativas y positivas sobre los hablantes y

1. Puede consultarse Zavala et al. (2014) para el caso de políticas lingüísticas en la región de Apurímac. 
no hablantes de quechua que los jóvenes enfrentan, construyen y transforman; y, finalmente, sus críticas y demandas para la enseñanza del quechua. Estos hallazgos surgen de veinte meses de trabajo de campo en dos secundarias de la región del Cusco.

Esta indagación se sitúa dentro del campo de la sociolingüística crítica (Niño Murcia et al., 2020) y la antropología lingüística, y contribuye a la investigación de la educación de lenguas minorizadas². Basándome en hallazgos etnográficos, busco aportar al desarrollo de una enseñanza de lenguas originarias en el nivel secundario que valore las trayectorias lingüísticas juveniles; expanda sus repertorios comunicativos; y cuestione las relaciones de poder que invalidan sus bilingüismos, identidades e intereses de aprendizaje.

El creciente reconocimiento de la población originaria en contextos urbanos evidenciada en el último censo peruano (Andrade, 2019) es un llamado urgente para comprender cómo se realiza la educación de y en lenguas originarias en estos contextos, con miras a mejorar e incrementar esta oferta. Escuchar las voces de los jóvenes es crucial en esta labor, en tanto ellos no solo son los hablantes presentes y futuros de las lenguas originarias, sino también pueden convertirse en agentes claves en la reclamación lingüística y cultural de sus pueblos originarios (Leonard, 2012). Sin embargo, muchas veces se minimiza su interés e involucramiento en estos proyectos (Córdova, 2015; Sumida Huaman, 2014). Conocer el bilingüismo e identidad juvenil, entonces, nos incumbe si queremos crear experiencias educativas en las que los jóvenes se reconozcan y sean reconocidos como actores en la construcción de la EIB.

\section{Bilingüismo e identidad desde las prácticas sociales}

A continuación, presento los supuestos teóricos y conceptos analíticos que guían mi análisis sobre la identidad y el bilingüismo juvenil en los Andes, y sus implicancias para la enseñanza de lenguas originarias en contextos urbanos.

\section{Bilingüismo como práctica social}

Mi acercamiento al estudio del bilingüismo se sitúa en una larga tradición sociolingüística que entiende al lenguaje como una práctica social (Hymes, 1972). Bajo esta mirada, se busca comprender las maneras en que las personas bilingües utilizan una variedad de recursos comunicativos para comunicarse, dar significado, y negociar sus mundos sociales e imágenes de ellos mismos y de otros (Blackledge y Creese, 2010; García, 2009). En contraste a posturas que sitúan a lenguas, comunidades e identidades delimitadas, fijas y separadas como los pilares del bilingüismo, esta perspectiva enfatiza los "recursos puestos

2. Por minorizadas, a diferencia del término minoritarias, hago hincapié en el proceso histórico por el cual estas lenguas han sido socialmente establecidas como minoritarias en relación con otras lenguas mayoritarias. 
en juego por los actores sociales, en condiciones sociales e históricas que tanto limitan como hacen posible la reproducción social de las convenciones y relaciones existentes, así como la producción de nuevas relaciones" (Heller, 2020, p. 135). Esta mirada crítica del bilingüismo nos ayuda a dar cuenta de los significados ideológicos de los recursos lingüísticos, su distribución desigual en diversas espacios o redes de interacción social, y el potencial de las prácticas lingüísticas de los hablantes $-\mathrm{y}$ no necesariamente de las lenguas como sistemas delimitados- para reproducir y transformar el orden social.

El estudio del bilingüismo como práctica social parte desde la perspectiva de las prácticas y significados de y para los bilingües y no desde los códigos lingüísticos. Los conceptos de repertorio comunicativo y trayectorias lingüísticas ofrecen herramientas analíticas útiles para esta tarea. Para Jan Blommaert y Ad Backus (2013), el repertorio comunicativo constituye la colección o el conjunto de recursos comunicativos que los hablantes despliegan para participar en diversas prácticas sociales, y pertenece a individuos y no a comunidades lingüísticas. Los repertorios comunicativos incluyen recursos lingüísticos y no-lingüísticos, el conocimiento de cómo utilizarlos y las valoraciones que se tiene de estos. Estos repertorios se organizan biográficamente, y, por ende, las trayectorias bilingües no son iguales a lo largo de la vida ni tampoco predecibles. En palabras de Blommaert y Backus (2013),

Los repertorios nos permiten documentar con mayor detalle las trayectorias de los individuos a través de sus vidas: las oportunidades, limitaciones, y las desigualdades que encontraron, los contextos de aprendizaje a los que tuvieron acceso ( $\mathrm{y}$ a los que no tuvieron acceso), su movimiento a través de espacios físicos y sociales, su potencial de ejercer su voz en determinadas esferas sociales. (p. 24, traducción propia)

Vistas de esta manera, las prácticas bilingües no están relacionadas únicamente a cuestiones de dominio ni cumplen solamente fines comunicativos. Por el contrario, estas reflejan y se ven influenciadas por relaciones de poder y además cumplen fines identitarios (Unamuno, 2013). La identidad, por su parte, no es asumida como lo que los individuos tienen, sino, más bien, desde un enfoque sociocultural, es entendida como las maneras en que los individuos se posicionan y son posicionados por otros a través de las prácticas sociales, y específicamente, a través del discurso (Bucholtz y Hall, 2005).

\section{Modelos de persona ${ }^{3}$}

Adentrarnos al estudio del bilingüismo y su relación con la identidad nos permite comprender cómo el uso de una lengua está estrechamente vinculado con lo que significa ser o reconocerse como hablante de la lengua. En ese marco, nos

3. En inglés, se le conoce como "figures or models of personhood" (Agha, 2007). 
interesa conocer cuáles son las representaciones sobre los hablantes de quechua que circulaban en el mundo social juvenil y cómo impactaban en el desarrollo identitario de los jóvenes. La antropología lingüística ofrece herramientas para entender el surgimiento de las identidades sociales a través de la interacción (Agha, 2007; Wortham, 2005). Para Asif Agha (2007), la identidad social de un individuo emerge cuando ciertos signos (como gestos, comportamientos verbales, vestimenta, etc.) son asociados o reconocidos de manera indexical con distintos modelos de ser, es decir, cuando ciertos signos apuntan o son vinculados a distintos modelos de persona. Estos modelos de persona no se refieren a personas reales o biográficas, sino a estereotipos o categorías sociales que circulan de manera local o también más ampliamente, y que suelen ser reconocibles a través del habla. Los modelos de persona incluyen evaluaciones sobre cualidades personales, formas de relacionarse y conductas (Agha, 2007).

Por ejemplo, en mi contexto de investigación, un modelo de persona prevalente era el del quechua hablante, un modelo de larga circulación, que representaba a una persona monolingüe en quechua, con orígenes rurales, y asociada con la ignorancia y el retraso. Otro modelo de persona era el extranjero, que representaba a un joven que no hablaba quechua, no tenía interés en aprenderlo, y no se identificaba con su lengua o cultura. Desde esta mirada, estudiar la identidad no se limita a entender características o cualidades personales o de personalidad, sino, más bien, se enfoca en entender cómo se atribuyen distintos modelos culturales de personas a los individuos en la interacción, y, también, cómo los individuos se acercan o se distancian de estos modelos. En este sentido, los modelos de personas que analizaré ofrecen miradas émicas para conocer las representaciones de los hablantes de quechua existentes en un contexto de educación secundaria. Asimismo, permiten entender cómo los docentes y los estudiantes reproducen; resignifican; $y$, a su vez, cuestionan estas asociaciones identitarias con consecuencias para las experiencias educativas juveniles.

\section{Una aproximación etnográfica}

El estudio del bilingüismo e identidad desde las prácticas sociales requiere de un enfoque metodológico afín. La etnografía, entendida no solo como un conjunto de métodos de investigación, sino sobre todo como un paradigma de investigación, permite abordar el estudio del lenguaje como parte de y constituyente de la vida social (Blommaert, 2009). A través de un enfoque etnográfico sociolingüístico, busco describir prácticas lingüísticas e identitarias de manera detallada y situada, rechazando supuestos a priori, y privilegiando las perspectivas émicas y los significados que los individuos dan a estas prácticas (Wolcott, 1987).

Tomando en cuenta los aportes de la etnografía crítica, también presto atención a cómo las prácticas bilingües y educativas se encuentran inmersas en dinámicas de poder, y a cómo los sujetos mantienen y transforman estas dinámicas (Martin-Jones, 2007). Finalmente, desde los estudios de la etnografía 
de la juventud, rescato la importancia de guiar el quehacer investigativo - tanto proceso y producto- desde una postura que reconozca la complejidad de lo que significa ser y hacer como sujetos jóvenes, y que cuestione las desigualdades y representaciones dominantes que estos afrontan (Paris y Winn, 2013).

\section{Contexto y participantes}

Durante los años 2016 y 2017, realicé trabajo de campo etnográfico y participativo en dos secundarias de la provincia de Urubamba, ubicada en la región del Cusco, donde se dictaba un curso de quechua como una asignatura con duración de 45 minutos semanales. Las secundarias eran colegios públicos mixtos, con un total de 519 y 499 estudiantes respectivamente. Urubamba, capital de la provincia del mismo nombre, tiene una población de 20.822 habitantes (INEI, 2017), y es el centro de comercio y gobierno para los habitantes de pueblos y comunidades aledañas ubicadas en el piso de valle y en las alturas. La población de Urubamba y la que transita por ella, son multilingües. Cuando uno camina por sus calles, escucha el quechua y el castellano en conversaciones cotidianas, y algunas lenguas extranjeras utilizadas mayormente por viajeros y turistas.

Las dos secundarias donde realicé trabajo de campo contaban con distintas experiencias de enseñanza del quechua y perfiles estudiantiles, criterios importantes para su selección, pues me permitió conocer la diversidad del bilingüismo juvenil y de las prácticas educativas en la zona. En una de las secundarias, se impartía el curso desde hace más de catorce años, mucho antes de la introducción de la normativa regional. La maestra, quien enseñaba a todos los grados, contaba con vasta experiencia como docente de quechua, amplia formación y conocimiento de la gramática de la lengua y fluidez en la lengua. En el segundo colegio, las clases de quechua iniciaron en el 2011 y no se contaba con docentes especializados en esta área. En su mayoría, se asignaba el curso a docentes contratados que no contaban con experiencia ni formación previa en enseñanza de lenguas (originarias), ni un currículo o materiales con los cuales trabajar. Todos los docentes eran bilingües quechua-castellano, la mayoría contaba con habilidades productivas orales desarrolladas y pocos se sentían cómodos escribiendo en quechua. En ambos colegios, la enseñanza del quechua transcurría en un contexto desafiante, caracterizado por el tiempo limitado; la carencia de recursos y lineamientos educativos ${ }^{4}$; y la falta de apoyo de formación para los docentes, quienes además lidiaban con la transición a la modalidad Jornada Escolar Completa durante el estudio, y con aulas con un promedio de 30 estudiantes. Los docentes tampoco contaban con formación en educación bilingüe o interculturalidad.

La población estudiantil, como veremos, representaba una diversidad de perfiles y trayectorias multilingües. En una de las escuelas, estudiaban jóvenes

4. Durante este estudio no se contaba con lineamientos nacionales ni regionales para un modelo de atención EIB urbana. 
que en su mayoría habían nacido y crecido en comunidades rurales, mientras que, en la otra, se contaba con una mayor proporción de estudiantes provenientes de áreas urbanas. No obstante, cabe anotar que ambas escuelas contaban con estudiantes quienes habían crecido en un ir y venir entre diferentes espacios, fuera y dentro de la provincia y región en cuestión. La mayoría de los jóvenes de ambas escuelas estudiaba quechua por primera vez en la secundaria, con excepción de algunos que aprendieron algo de quechua en diferentes momentos de su primaria y otros que asistieron a primarias bilingües.

\section{Recolección y análisis de datos}

Los métodos de recolección de datos incluyeron observación participante en las secundarias, en más de 200 clases de quechua de distintos grados; entrevistas semiestructuradas con 8 docentes de quechua y 70 jóvenes ${ }^{5}$; encuestas sociolingüísticas con 353 estudiantes; recolección de documentos educativos; grabación de audios y videos durante las observaciones; e investigación colaborativa con una docente. Los tipos de datos recolectados fueron influenciados por mis identidades y las relaciones que desarrollé con los participantes. En ambos colegios, asumí el rol de voluntaria de las clases de quechua, apoyando a algunos docentes con la planificación de clases y, más frecuentemente, apoyando a los estudiantes en actividades de aula. Mis habilidades en castellano - lengua con la que crecí- y en quechua -lengua que comencé a aprender en la universidad y continúe desarrollando en interacciones cotidianas durante mi trabajo de campo-me permitieron comprender y recolectar datos bilingües de las aulas. Como una mujer peruana joven y no-indígena, mi edad ${ }^{6}$, mi participación en diversas actividades escolares (pasacalles, celebraciones, viajes, campeonatos, reuniones), mis visitas a los hogares de algunos estudiantes, y mi interés en el quechua y en seguir aprendiendo el idioma junto a los docentes y estudiantes, me permitieron relacionarme con ellos y ser parte de las secundarias estudiadas.

Para el análisis, utilicé la técnica cualitativa de codificación abierta y enfocada (Miles et al., 2014) durante y después del trabajo de campo, lo cual se complementó con el análisis temático de datos de algunos jóvenes focales, y análisis del discurso de transcripciones de entrevistas y grabaciones. Los diferentes roles que asumí durante los veinte meses de investigación etnográfica, la triangulación de diferentes métodos de recolección y análisis de datos, la diversidad de los datos, y el involucramiento de participantes en distintas etapas de la investigación contribuyen con la validez del estudio?

5. Se hizo uso de fotografías, videos y mapas lingüísticos, y se compartieron datos etnográficos e interaccionales para un análisis participativo.

6. En ese período, estaba en mis veinte.

7. Para una descripción detallada de la metodología del estudio, puede consultar a Kvietok (2019). 


\section{Miradas etnográficas: bilingüismo, identidad y la enseñanza del quechua}

A continuación, presento hallazgos etnográficos que muestran la diversidad y complejidad del bilingüismo e identidad juvenil en contextos urbanos de enseñanza del quechua.

\section{Repertorios comunicativos y trayectorias lingüísticas}

Durante mi trabajo de campo, identifiqué a tres grupos de jóvenes bilingües - de comunidades de altura, del valle y no hablantes ${ }^{8}$ - cuyos repertorios y trayectorias pueden ayudarnos a entender quiénes son los estudiantes de quechua, y otras lenguas originarias, en contextos urbanos.

Los jóvenes provenientes de pueblos alto-andinos habían nacido y crecido en comunidades donde el quechua fue la lengua de socialización primaria. Así, la identificaban como su lengua materna, la que aprendieron primero y/o la lengua de interacción con sus padres, la mayoría quechua-hablantes con poco dominio del castellano. Sin embargo, para los jóvenes, su uso y dominio del quechua no había sido constante ni fijo a lo largo de sus vidas. La falta de oportunidades de escolarización bilingüe significaba que algunos no habían tenido oportunidades de aprender a leer o a escribir en su lengua materna. Además, los altos costos de usar el quechua fuera de sus comunidades muchas veces generaban que dejaran de lado su uso al migrar a centros urbanos. Daniel, ${ }^{9}$ quien estudiaba el segundo grado cuando lo conocí, describió que, al migrar a la ciudad para estudiar la secundaria, hubo una época en la que dejó de hablar quechua hasta el punto en que le era difícil utilizarlo con sus padres al retornar a su comunidad. Al mismo tiempo, el dominio de castellano de estos jóvenes era escudriñado en ámbitos escolares urbanos, donde la influencia del quechua en su castellano los hacía objeto de burla de sus compañeros y, a veces, implicaba que se cuestione su capacidad de aprendizaje. El cuestionamiento de sus habilidades en castellano contrastaba con el uso especializado que hacían de él al actuar como intérpretes para sus familiares en diversos contextos institucionales o al responsabilizarse de enseñar esta lengua a sus hermanos menores, como en el caso de Daniel.

El segundo grupo de jóvenes nacieron y/o crecieron en distintas ciudades, pueblos y comunidades del Valle Sagrado. Para ellos, tanto el quechua como el castellano eran parte de sus repertorios comunicativos de infancia. Algunos identificaban haber aprendido una lengua primero y después la otra, mientras que otros aprendieron ambas simultáneamente. A diferencia del grupo anterior, para

8. Algunos jóvenes se autoidentificaban con estas designaciones, y otros eran identificados de esa manera por sus compañeros y docentes.

9. Desde este punto en adelante, se usan seudónimos para proteger el anonimato de los participantes. 
estos jóvenes, el quechua nunca fue la lengua de comunicación con sus padres o hermanos durante su niñez. Mientras que sus padres no les habían enseñado la lengua para protegerlos de la discriminación que ellos habían experimentado como bilingües, sus abuelos habían asumido el rol de agentes socializadores del quechua. En respuesta a mi pregunta sobre como aprendió quechua, Giancarlo, quien identificaba al castellano como su primera lengua, me contó:

en dos meses, aprendí el idioma quechua, porque yo tenía digamos tres años. Pero mi mamá tenía una operación; tuvo que estar en el hospital y yo me quedé donde mi abuela ... y mi abuela hablaba en quechua, teníami entorno era puro quechua. $\mathrm{O}$ sea, en ese momento me aprendí, pero me había olvidado el castellano $\left(\mathrm{E}, 2017^{10}\right)$.

Esta reflexión da cuenta de cómo las distinciones entre primera y segunda lengua no son siempre pertinentes, o suficientes, para entender o describir las experiencias y habilidades bilingües, las cuales cambian a lo largo de la vida (García, 2009). Para Giancarlo, el dinamismo de su repertorio incluye cambios de dominio bilingüe en sus primeros años de vida como resultado de un nuevo contexto de socialización. Además, durante su infancia y adolescencia, Giancarlo pasó de olvidar su castellano a olvidar su quechua cuando dejó de vivir con su abuela, época en que "pensé que el quechua se me estaba muriendo adentro". La mayoría de estos jóvenes experimentaron puntos de quiebre en sus trayectorias lingüísticas. A veces, estos puntos los acercaban al quechua como convivir con abuelos quechua hablantes y llevar un curso de quechua en la primaria - y, otras veces, los alejaban del idioma - como el distanciamiento con sus abuelos, políticas lingüísticas familiares y escuelas monolingües en castellano-.

Finalmente, el tercer grupo de jóvenes se identificaban como no-hablantes del quechua y no habían tenido oportunidades significativas para aprender o escuchar el idioma durante su infancia. Algunos recordaban a parientes que hablaban quechua en ámbitos familiares, pero ellos no se reconocían ni se sentían reconocidos como interlocutores válidos. En palabras de Pedro, "es que conmigo no hablaban, ni con mis papás... hablaban a veces con algunos familiares de ellos o primos... pero nunca de verdad hablaban" (E, 2017). Algunos jóvenes mencionaron que escuchar el idioma se les hacía algo "desconocido" o "extraño", y durante su infancia comenzaron a aprender idiomas extranjeros como el inglés e italiano, los cuales eran usados por sus parientes por motivos de trabajo - en una región con alto porcentaje de turistas extranjeros-, o por ser su lengua materna y parte de su herencia familiar ${ }^{11}$.

10. E se refiere a entrevistas; NC a notas de campo; A a grabaciones de audio; y ES a encuesta sociolingüística.

11. En entrevistas con jóvenes pertenecientes a estos tres grupos, también identifiqué que algunos tenían contacto con otras lenguas indígenas y hasta habilidades lingüísticas 
Además del dinamismo de sus trayectorias, otro punto en común entre estos jóvenes es haber experimentado cuestionamientos sobre su condición de bilingües. Mientras que para los jóvenes de altura el quechua era visto como un problema que impedía el desarrollo de su castellano y habilidades escolares, para los jóvenes de los otros grupos, su condición como hablantes del quechua era invisibilizada o criticada. Varios de ellos describían haber experimentado desencuentros con el quechua al no poder entender o comunicarse con familiares o adultos mayores. También, habían recibido evaluaciones negativas sobre su interés por el aprendizaje de esta lengua, como veremos en la siguiente sección. La falta de oportunidades para desarrollar un bilingüismo quechuacastellano dejaba a muchos de ellos con sentimientos de inseguridad e incomodidad frente al quechua. Alonso, a quien conocí a sus 12 años, me contó que solía sentirse "como de estorbo" dentro de su familia, debido a que era el único que no podía entender quechua y malograba las reuniones familiares donde contaban cuentos, pues constantemente tenía preguntar qué decían:

... siempre se siente algo raro, ¿no? Tú eres el único que no entiende, $¿$ no? Que te sientes medio raro y necesitas aprender necesariamente. Por ejemplo, en un salón, todos saben sumar y tú no sabes sumar. ¿Cómo te sientes? Medio así como "yo soy diferente”... (E, 2017).

No obstante, estos sentimientos de desconexión llevaron a algunos jóvenes a realizar esfuerzos personales para transformar sus repertorios. En el caso de Giancarlo, después de que dejó de vivir con su abuela, tomó la decisión de comenzar a conversar con personas mayores que hablaban quechua, y responderles en este idioma, y preguntar a sus padres el significado de palabras en quechua que no entendía. Para Giancarlo, estas acciones representaron otro punto de quiebre en su trayectoria bilingüe: "Ahí fue cuando hice resucitar de nuevo el quechua y empecé a hablar y no olvidarme" (E, 2017). Vemos, entonces, la forma como los jóvenes también transformaban el orden social en el que se encontraban y reconfiguraban sus repertorios.

Las visiones a futuro de los tres grupos de jóvenes también ayudan a entender los anhelos, las preocupaciones y las incertidumbres que compartían en relación con su bilingüismo. Los jóvenes de altura, por ejemplo, compartían la convicción de que el quechua siempre sería parte de sus repertorios comunicativos: "desde chiquito me ha acompañado ya ese idioma ... ya está grabado en mi mente bien" (Daniel, E, 2018). Sin embargo, reconocían que este no era el caso para todas las personas de su generación o todos los jóvenes de sus comunidades. Algunos de ellos tenían interés por enseñar la lengua a sus futuros hijos o por convertirse en profesores bilingües o de quechua. Por otra parte, los jóvenes del valle compartían la expectativa de mantener el quechua, sobre todo 
a nivel de sus habilidades receptivas orales; no obstante, expresaban la necesidad de apoyo, ya fuera de sus familias o cursos adicionales, debido a que por sí solos no podían asegurar el logro de estos anhelos. Finalmente, para el tercer grupo, la continuidad del quechua en sus vidas se veía cargada de incertidumbre. Aunque los jóvenes reconocían el valor estético y utilitario de la lengua a nivel profesional, cuestionaban la relevancia del idioma si trabajaban fuera de zonas altoandinas o del Cusco, y, además, no sentían que tenían el apoyo necesario de sus familias para su aprendizaje. Si bien expresaban preocupación sobre el desplazamiento del quechua, ninguno se percibía como un agente revitalizador de la lengua, una postura que los dejaba con ambivalencias, en palabras de Pedro: "Digo que el idioma se está muriendo y no hacemos nada. Yo tampoco hago nada y me siento mal también por eso".

Desde la sociolingüística crítica, se ha alertado sobre una visión dominante que se restringe a entender al bilingüismo como la sumatoria de lenguas o al bilingüe como alguien con igual uso de estas lenguas en distintos dominios o a través del tiempo (Heller 2020; Unamuno, 2013). En contraste, los testimonios de estos jóvenes nos demuestran el dinamismo y la heterogeneidad de sus trayectorias lingüísticas; las diversas fuerzas que cuestionan, subestiman o niegan su condición de bilingües; y las consecuencias simbólicas y materiales vinculadas a sus identidades y prácticas bilingües.

\section{Representaciones negativas sobre los (no) hablantes de quechua}

La enseñanza del quechua en las secundarias tenía como objetivo promover el uso y aprendizaje de la lengua por parte de los jóvenes y, en algunos casos, un sentido de pertenencia cultural. Sin embargo, en mis observaciones y conversaciones con estudiantes, pude identificar cómo las escuelas y aulas de quechua eran espacios donde circulaban y se reproducían representaciones negativas sobre los jóvenes como hablantes y no-hablantes de quechua. Es decir, se trataba de espacios donde se encontraban presentes los modelos de persona del quechua hablante y del extranjero con consecuencias negativas para los jóvenes.

Aunque la mayoría de los estudiantes eran bilingües quechua-castellano, reconocerse o ser reconocido como un quechua hablante llevaba un significado particular. Para los jóvenes, ser un quechua hablante era equiparado con ser un hablante de quechua como lengua materna, con habilidades limitadas del castellano, y proveniente de zonas rurales, principalmente, de comunidades de altura. Aunque varios mencionaban apreciar ciertas habilidades de este grupo de personas - como la pureza o el habla dulce del quechua-, el quechua hablante era generalmente reconocido como un tipo de persona del que los jóvenes buscaban distanciarse; sobre todo, se esforzaban por no ser reconocidos como tales. Esta asociación ideológica entre los hablantes del quechua $-\mathrm{y}$ otras lenguas originarias $-\mathrm{y}$ nociones de ignorancia, inferioridad $\mathrm{y}$ atraso tiene raíces coloniales y racializadas, y, aunque ha sido criticada desde diversas perspectivas, prevalece en nuestra sociedad (Huayhua, 2017). 
En este sentido, para varios jóvenes de altura, sus escuelas urbanas eran espacios inseguros para el uso del quechua y para identificarse como hablantes de esta lengua. En el siguiente fragmento, Daniel narra sus experiencias en clase de quechua al comienzo del año:

... en esos momentos, nadie todavía sabía. Yo también, como si no habría sabido quechua. Los profesores [preguntaban] “iqué cosa significa esto?"... Sabiendo yo, no les respondía pe, pero ¿qué cosa me dirán mis compañeros? Así, yo miraba así. Les miro, ¿no? No les decía nada. Ya poco a poco, así pasando cuatro meses así, tareas dejan así ya. Me dijeron "Tú eres el único que ha hecho bien”... poco a poco, ya, casi la mayoría ya sabe... se van enterando. (E, 2018)

Llama la atención que la clase de quechua, un espacio donde se busca promover el uso de esta lengua y donde jóvenes como Daniel pueden reconocerse como hablantes, sea un espacio donde es necesario encubrir su repertorio (McCarty et al., 2009), una práctica de protección frente a la discriminación experimentada o anticipada por parte de sus compañeros. Asimismo, resalta el hecho de que este proceso se repetía cada año: pasar a un nuevo grado frecuentemente significaba un cambio de docente y de compañeros, dinámicas que los jóvenes debían tomar en cuenta al ser posicionados, o posicionarse, como hablantes de quechua. El temor de ser identificado como un quechua hablante repercutía también en jóvenes provenientes de comunidades de piso de valle. En algunos casos, este temor los llevaba a encubrir sus habilidades lingüísticas en quechua y a evitar identificarse como hablantes.

Para los jóvenes de altura, el alto costo de ser identificado como quechua hablante también estaba relacionado con la inspección de su bilingüismo y otras características personales por parte de sus compañeros. Sus testimonios, y mis observaciones de aula, dan cuenta de cómo el uso de un castellano no-estándar, o motoso ${ }^{12}$, de los bilingües de zonas rurales era objeto de burla. Quienes participaban en este escrutinio - que tomaba la forma de repeticiones de frases motosas o risas - justificaban estas prácticas como "bromita nomás" con la intención de "ayudar" a que sus compañeros "mejoren" su castellano; sin embargo, los jóvenes que eran objeto de este escrutinio no lo veían de la misma manera. En palabras de Yeny, "me hacían sentir mal... Es feo digamos que se te salga algo y ... se rían todos... Hay momentos que te atormenta, pues" (E, 2017). La estigmatización del castellano con influencia del quechua solía ocurrir en grupos pequeños y entre compañeros, rara vez frente a docentes, y también tomaba la forma de imitaciones de frases motosas por parte de estudiantes bilingües con mayor dominio del castellano. Mientras que jóvenes como Yeny

12. El motoseo es un fenómeno lingüístico altamente estigmatizado y que reproduce la racialización de hablantes de quechua (Zavala y Córdova, 2010). 
optaban por mantenerse callados y tratar de mejorar su habla, algunos hacían frente a este tipo de discriminación:

Les dije, por favor, dejen de molestar... Mi carácter es un poco fuerte y, por eso, les dije. Por eso, me han dicho "no, solo era broma", "no me gusta ese tipo de bromas". Asi, ya les paré y ya no me molestaron (Maribel, E, 2017).

Los jóvenes del valle o no-hablantes describían a sus compañeros que producían el mote como personas que se sentían inferiores, se avergonzaban del quechua, "más sumisos, tímidos"; y, en algunos casos, con menos habilidades escolares. Durante mi trabajo de campo, observé pocas oportunidades en las aulas para deconstruir las asociaciones existentes entre ser una persona del campo hablante de quechua y estas evaluaciones negativas. La falta de oportunidades de (des)aprendizaje repercutía directamente en los objetivos de enseñanza del quechua que se planteaban los docentes. En este sentido, la enseñanza de las lenguas originarias no puede enfocarse solamente en la valoración de una lengua, resaltando su legado histórico o sus características lingüísticas, sino que tiene que implicarse en desafiar las representaciones sobre los hablantes de la lengua y las consecuencias que estas acarrean en sus vidas.

Como se mencionó previamente, otro de los modelos de persona que circulaban en las escuelas secundarias era el extranjero. Por un lado, los docentes solían llamar a los jóvenes que no participaban o decían no saber la lengua con nombres como "extranjeros" o "gringos" mentarios que, a veces, iban dirigidos a los estudiantes $y$, otras veces, hacían referencia a ellos. Por otro lado, los supuestos detrás de este modelo impactaban en las orientaciones de los docentes hacia sus estudiantes, puesto que los jóvenes muchas veces no se encontraban a la altura de sus expectativas. Dentro de clase, observé cómo las habilidades comunicativas de algunos jóvenes, su participación en clase, y su identificación con el quechua, eran evaluadas por los docentes de manera que los posicionaban como desinteresados en el quechua. Este era el caso de Milagros, quien se identificaba como no-hablante del quechua y quien no había tenido oportunidades de aprender el idioma de niña. El siguiente evento de aula ejemplifica estas evaluaciones:

Profesora: su papá habla quechua, habla todo [hablando sobre Milagros, dirigiéndose a otro estudiante]

Milagros: ¿qué?

Profesora: claro, yo le he enseñado [dirigiéndose a Milagros]

Milagros: profesora mi mamá-

13. También, usaban otras nacionalidades, como "chileno". 
Profesora: es que no les gusta. No quieren. No quieren hablar; es otra cosa,

Milagros: profesora mi mamá y mis papás hablan quechua. Mi mamá ha aprendido a hablar quechua después. Mi papá lo habla desde que era niño, pero a mí no me han hablado en quechua-

Profesora: mamita, ¿pero no escuchas lo que hablan tus abuelitos? Lo que hablan tus-

Milagros: no vivo con mis abuelitos. Mis abuelitos han muerto y mi abuelita no me habla quechua: me habla castellano

Profesora: [dirigiéndose al resto del salón] a ver lo único que quiero es, simplemente- hagan los que quieren y los que no quieren lo siento pues, así es, se acabó del problema.

(NC y A, 2016)

La profesora basa sus evaluaciones en su conocimiento del bilingüismo de los familiares de Milagros y la suposición de que el quechua se continuaba transmitiendo en su familia, experiencia ajena a varios jóvenes. De hecho, muchos docentes suponían que el origen rural de los estudiantes y/o de sus familiares, el dominio del quechua de familiares adultos, o el dominio del idioma que sus estudiantes tenían de niños significaba que los jóvenes deberían comunicarse en el idioma y dentro de la clase de quechua. Los docentes explicaban la poca participación oral de los estudiantes y sus rechazos de participar como muestra de falta de gusto por la lengua. Así, los posicionaban como - y los llamaban- extranjeros. En contraste, los jóvenes explicaban su poca participación por la falta de habilidades lingüísticas en quechua y la falta de oportunidades para desarrollarlas.

Ser identificado como un extranjero causaba frustración y sentimientos de incomodidad en los jóvenes. Al reflexionar sobre el evento anterior, Milagros me comentó: "Me sentí muy mal, la verdad. Sentí impotencia por tratar de responderle, pero tampoco quería responderle, porque no sé, no le dije nada. Solo le miré, pero me hizo sentir muy mal" (E, 2016). Identificar a estos jóvenes como desinteresados o jóvenes que negaban saber o hablar el quechua (Kvietok, 2021) no aumentaba su participaran en clase. ¿Quién, finalmente, desearía participar en clase cuando su trayectoria bilingüe es cuestionada y en un contexto con pocos andamiajes para aquellos con pocas habilidades productivas en la lengua? Asimismo, estas evaluaciones hacían poco —o nada- para contrarrestar las situaciones en que los jóvenes evaluaban a sus compañeros usando los mismos términos. De hecho, es posible que contribuyera a replicar estas evaluaciones identitarias. Alguna vez observé cómo a una alumna que acababa de llegar a Urubamba de la ciudad de Lima y que no tenía familiares quechua hablantes se la acusaba de hacerse la que no sabía el quechua por sus nuevos compañeros de salón cuando pedía apoyo y traducciones durante clase. 
Las evaluaciones de los jóvenes, informadas por los supuestos del modelo del extranjero, no permitían a los docentes conocer realmente las trayectorias lingüísticas de sus estudiantes en un contexto de desplazamiento lingüístico ni tampoco aproximarse a sus necesidades de aprendizaje. Estas evaluaciones dan a conocer las brechas entre las experiencias de socialización de los docentes y los jóvenes, y la falta de oportunidades que los docentes habían tenido para aprender sobre el bilingüismo estudiantil, aspecto que también ha sido observado en otros contextos de educación indígena (Hecht, 2018). A pesar de las diferencias entre los jóvenes a quienes se les identificaba como quechua hablantes o extranjeros, observamos cómo ambas representaciones no contribuían a crear un sentido de pertenencia en la comunidad de aprendizaje ni a procesos de adueñamiento (Guerrettaz, 2020) de la lengua por parte de los jóvenes. Vale la pena preguntarse cuáles eran las representaciones positivas acerca de los jóvenes como hablantes de quechua que circulaban en las secundarias.

\section{Representaciones positivas sobre los hablantes de quechua}

Durante mi trabajo de campo, pedí a algunos jóvenes que tomaran fotos de personas, lugares o cosas que les hiciera pensar en el quechua, buscando conocer desde su punto de vista los significados que asignaban hacia la lengua y sus hablantes. Una de las fotos que tomó Raúl, estudiante de primero de secundaria, era la de un sticker de un inca y una qolla, que había pegado en la pared de su cuarto (ver Figura 1). Al preguntarle por qué había tomado esa foto me respondió: "Es de quechua, ¿o no?... porque los incas hablaban quechua y representaban a la lengua de quechua" (E, 2016).

Figura 1

Foto de Raúl

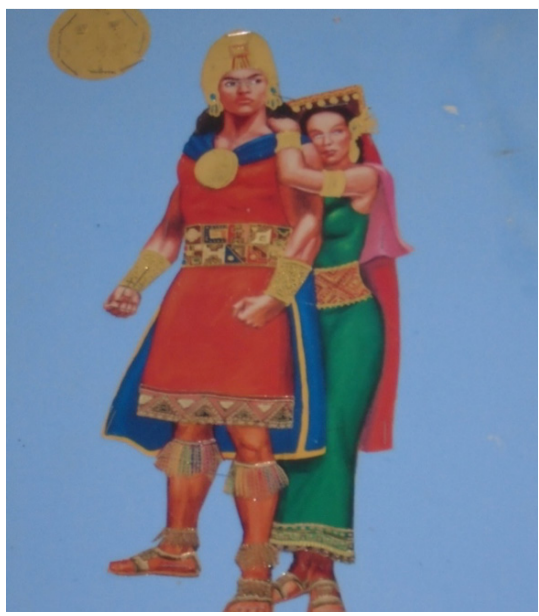


La foto y el comentario de Raúl dan cuenta de un discurso muy poderoso que vincula al quechua con la herencia inca, presente en las secundarias y en la sociedad. Desde esta mirada, el ser un cusqueño con identidad - otro modelo de persona-implicaba ser una persona con orígenes en la región andina del Cusco que reconoce la importancia del legado incaico y aprecia la lengua quechua, aunque no necesariamente la habla o utiliza con un dominio avanzado. Esta representación de la identidad regional cusqueña no está libre de cuestionamientos, pues promueve una asociación del valor del quechua con el pasado (glorificado) incaico, invisibilizando las prácticas culturales contemporáneas de los quechuas y habitantes andinos (ver también Mendoza, 2008). Además, dicha representación puede ir de la mano con posturas que minimizan o inferiorizan otras variantes del quechua por no considerarlas "verdaderas" (Coronel-Molina, 2015) ${ }^{14}$.

El punto a resaltar, no obstante, refiere a los significados que los jóvenes le asignaban a este modelo de persona, es decir, cómo y para qué se posicionaban en relación con esta representación de hablante. En general, hacían referencia o se identificaban con este modelo para explicar la importancia de la enseñanza del quechua, compartir su apreciación hacia la lengua y cultura, y para cuestionar la discriminación lingüística. Con respecto al primer significado, varios jóvenes justificaban la necesidad de enseñar el quechua en sus escuelas reconociendo que era su "lengua materna": "Nosotros como peruanos deberíamosprimero es el quechua, como lengua mater, que es de acá de nuestra localidad, como serranos que somos". En segundo lugar, reconocerse como un cusqueño con identidad estaba ligado a deseos de relacionarse más con su herencia familiar y cultural. Kike, por ejemplo, explicó su anhelo de esta manera:

... lo que yo quisiera es tener un apellido inca, de verdad porque, porque mi abuelo, mis abuelos, mi bisabuelo llevaba apellido Yupanqui y mi abuelita llevaba el apellido... de un Inca... Y no entiendo cómo se ha perdido, porque deberían de sobresaltar el quechua- el apellido quechua, ¿no? A veces, me avergüenzo de mi propio apellido, porque no es que no tenga identidad de dónde vengo así, sino quiero identificarme más con la- mi cultura, pues. (E, 2016)

Finalmente, también observé cómo se moviliza el modelo del cusqueño con identidad para oponerse a burlas lingüísticas. Mientras conversaba con algunas alumnas durante un recreo, hablábamos sobre el uso del quechua en sus familias y ellas comentaban cómo sus abuelas solían usar el quechua cuando les castigaban. Una de ellas dio como ejemplo la frase "kunallanña waqtarusayki". Uno de sus compañeros, quien escuchaba nuestra conversación, tradujo esta frase al castellano: "te voy a sobar". De repente, una de las estudiantes se dirigió a él y le dijo: "Habías sabido quechua, yo pensaba que eras americano". Este

14. Agradezco a uno de los revisores por plantear esta observación. 
comentario despertó risas entre todos los presentes. Su compañero, sorprendido ante esta respuesta, le contestó: "Si los cusqueños hablan quechua" (NC y A, 2016). En esta interacción entre pares, vemos la manera como un estudiante invoca el modelo del cusqueño como hablante de quechua para defender sus habilidades bilingües frente a una compañera que subestimaba su repertorio comunicativo y quien, además, intentó de atribuirle la identidad de un joven desinteresado o un extranjero.

Entender las diversas posturas de los jóvenes en relación con el ser un cusqueño con identidad demuestra cómo le daban sentido a lo que significaba reconocerse como una persona bilingüe en contextos desalentadores y hostiles. Aunque esta representación incluía rasgos adicionales al hablar quechua como apreciación por el folklor andino y el patrimonio tangible incaico-, la identificación de los jóvenes con este modelo de persona nos muestra que no veían la competencia comunicativa en quechua separada de una conexión con su herencia cultural.

Al mismo tiempo, observé la ausencia de una identificación quechua o indígena explícita por parte de los jóvenes y docentes. Los jóvenes hacían referencia a los quechua hablantes o campesinos, o a una identidad regional cusqueña, pero no necesariamente se reconocían o reconocían a otros hablantes como miembros del pueblo o de pueblos quechuas. Esta ausencia no es sorprendente, puesto que la categoría de "indígena" u "originario" no circula en todas las esferas de los Andes (Huayhua, 2017). Nancy Hornberger (2014), por ejemplo, da a conocer el caso de una docente quechua quien afirma que "así hasta ser profesional, no, o sea conscientemente, no estaba de indígena" (p. 283). De esta manera, la docente narra cómo construyó su identidad indígena de manera reflexiva y consciente en el contexto de un programa de educación superior en EIB. Como esta docente, muchos jóvenes participaban en una serie de prácticas culturales quechuas fuera de la escuela sin identificarse explícitamente con esta identidad étnica. Volveré a este punto en la sección final para abordar la relación entre la enseñanza de lenguas originarias y la afirmación cultural.

Otro aspecto que resaltó durante el estudio fue que los jóvenes se identificaban de manera positiva como hablantes de quechua en interacciones cotidianas, posicionamientos alternativos a las representaciones negativas que enfrentaban más frecuentemente. Durante una clase de primero de secundaria, observé que Martín, quien solía participar en clase, mencionaba con soltura y sonriente "yo soy un crack de quechua" a sus compañeros, después de haber respondido a una pregunta de la maestra correctamente (NC, 2017). En otra ocasión, mientras varios estudiantes se lamentaban de no ser capaces de hacer la tarea que había asignado la docente, uno de sus compañeros, César, exclamó en voz alta: "Cinco soles la hora para profe de quechua", mientras levantaba la mano y se mostraba a sí mismo como capaz de enseñar la lengua a sus compañeros (NC, 2017). Aunque no eran actos extendidos, estos eventos nos muestran que los jóvenes se identificaban de manera positiva como hablantes y conocedores del idioma ante sus compañeros. Estos posicionamientos recibían 
respuestas positivas - como sonrisas y risas-, y no eran acompañados de burlas o evaluaciones negativas. Es importante recalcar que Martín y César provenían de comunidades del valle, eran bilingües con dominancia del castellano, y no habían vivenciado la racialización de su bilingüismo a diferencia de las trayectorias de los jóvenes de comunidades de altura. Desde esta condición de bilingües, por lo tanto, no enfrentaban los mismos riesgos de reconocerse como hablantes.

Estas identificaciones apuntan hacia la existencia de otro modelo de persona - más emergente que los anteriores-, que representa a alguien que se reconoce como hablante de quechua, quien hace uso del idioma con soltura en el contexto del aula de quechua y de manera abierta, y a quien no le importa las evaluaciones de los demás. Aunque personificar este modelo no era una posición accesible para todos, su movilización evidencia que los jóvenes postulaban nuevas maneras de identificarse con su bilingüismo. Si queremos que las escuelas sean espacios donde los jóvenes se identifiquen positivamente como bilingües, sería provechoso prestar atención a las maneras en que crean representaciones alternativas y las condiciones que las posibilitan.

\section{Críticas y demandas sobre la enseñanza del quechua}

En conversaciones con docentes, no solo era común escuchar que los jóvenes no querían hablar el quechua, sino también que no les importaba la clase de quechua ni querían aprender el idioma. Con respecto a estos comentarios, uno de los hallazgos relevantes es la coexistencia de posturas complejas y ambivalentes en relación con la enseñanza del quechua por parte de los jóvenes. Antes de presentar estas posturas, desarrollaré las prácticas educativas que predominaban en las aulas, enmarcadas en las condiciones desafiantes descritas anteriormente.

En la mayoría de clases de quechua que observé, predominaba una enseñanza enfocada en la gramática, la escritura y el vocabulario. Guadalupe Valdés (2015) utiliza el término de curricularización de la lengua ${ }^{15}$ para referirse a enfoques de enseñanza en contextos institucionales de enseñanza de lenguas, que promueven experiencias de aprendizaje descontextualizadas o desconectadas de las prácticas cotidianas de uso del lenguaje. Entre las prácticas observadas, prevalecía la enseñanza explícita de la gramática y la escritura del quechua. Además, se favorecía copiar reglas gramaticales, letras del alfabeto o listas de vocabulario de la pizarra, así como leer en voz alta o recitar canciones, poemas o adivinanzas. En palabras de Maribel, la clase de quechua consistía en "escribir, presentar, escribir, presentar... o aprender algunas palabritas". Para los docentes, esta curricularización del quechua buscaba legitimarlo como una lengua igual de válida que el castellano, y posicionar al curso de quechua en relación de igualdad con los de inglés o de comunicación en castellano.

15. El término en inglés es "language curricularization". 
Sin embargo, los jóvenes tomaban distintas posturas frente a este escenario de enseñanza. Por una parte, expresaban deseos de más oportunidades para desarrollar habilidades orales en quechua para comunicarse con sus compañeros y docentes. En conversación con dos compañeros de aula, uno de ellos expresó que deseaba que la clase fuera un espacio donde aprendieran a "comunicarnos... hablar con nosotros, digamos yo con él, pa que hablemos en quechua, eso debería enseñarnos" (E, 2018). Las oportunidades de participación oral a través de exposiciones orales muchas veces limitaban la participación de los estudiantes. Por un lado, como en el caso de Daniel, la persistencia del espectro de discriminación no creaba ambientes de confianza para expresarse en quechua. Otros estudiantes decían estar de acuerdo con las oportunidades de participación oral existentes -donde mayormente todos respondían en coro a las preguntas generadas por los docentes- explicando que esto minimizaba el riesgo de equivocarse o de ser identificado como hablante. Sin embargo, para muchos, las clases requerían demostrar habilidades productivas orales que se asumía que los jóvenes ya habían alcanzado, sin haber ofrecido antes andamiajes ni contextos seguros para que fueran desarrolladas.

Las actitudes de los jóvenes hacia la enseñanza de la escritura bordeaban entre la indiferencia y la frustración. La literacidad en quechua en el aula se organizaba alrededor de tres funciones: copiar discurso oral, realizar ejercicios de aula y representar los sonidos del quechua (Kvietok, 2019). Varios jóvenes describían el escribir en quechua como algo "muy difícil" y con "muchas reglas". Durante un trabajo grupal en que participaban alumnas con dominio oral de la lengua, las observé explicar a su maestra que, aunque ellas podían hablar quechua, al momento de escribir "nos palteamos, nos trabamos" (NC, 2016). Otros jóvenes optaban por no tomar mucha importancia a la escritura. Una vez que apoyé en la corrección de ejercicios, les pregunté a los miembros del grupo en cuestión que me contaran cómo había sido su experiencia al escribir. Uno de ellos me contestó: "Profe, hágase de la vista gorda nomás", y pidió que les firmara el trabajo (NC, 2017). Las actividades de escritura en el aula rara vez tenían propósitos o audiencias significativas para los jóvenes, quienes eran posicionados y asumían muchas veces el rol de escribanos en vez de autores de sus propios textos. En resumen, no veían la literacidad en quechua como una práctica de literacidad autogenerada en el contexto escolar o en sus vidas cotidianas (Barton y Hamilton, 2004). En palabras de Alonso, "escribiendo estarías mintiendo; alguien te lo estaría escribiendo... No vale mucho; en cambio, tú ya que estés hablando, ya sabes el significado... Quien sea escribe, pero pocos hablan".

El rechazo frente a la manera en que se desarrollaban las clases de quechua se manifestaba en distintos comportamientos de los jóvenes. Mientras algunos compartían su descontento con los docentes de manera verbal, otros lo expresaban llegando tarde o saltándose la clase, rehusando a participar en actividades y dedicándose a otras actividades no relacionadas con la sesión. Durante clases o recreos, algunos jóvenes compartieron sus quejas conmigo sobre los 
métodos de enseñanza. En entrevistas, me comentaron que el curso les parecía difícil, que se sentían perdidos o aburridos, o que lo detestaban.

Me parece crucial, sin embargo, separar las posturas de los jóvenes hacia el curso de quechua de sus posturas hacia la lengua en sí misma y sus expectativas de aprendizaje. Pedro, quien manifestó odiar la clase de quechua, me explicó que desarrolló su interés en el quechua recién en tercero de secundaria después de conocer la obra de José María Arguedas. Para ese entonces, sentía que era muy tarde para aprender, "porque ya hacían cosas un poquito más avanzadas y yo no podía; no entendía nada". Como Pedro, muchos jóvenes experimentaban una desconexión entre sus expectativas de aprendizaje y necesidades comunicativas, y las oportunidades de aprendizaje presentes en sus aulas. Por ejemplo, el 68\% de los alumnos encuestados manifestó que le gustaba hablar el quechua, y pensaba que era importante que se enseñase la lengua de sus ancestros y familias. El 32\% que respondió negativamente a esta pregunta brindó algunas de las siguientes razones: "no sé/no puedo hablar", "es difícil", "no entiendo/no comprendo", "no me gusta" (ES, 2016). Volviendo a los hallazgos etnográficos sobre las trayectorias bilingües juveniles, y considerando el contexto de enseñanza, podemos aproximarnos al porqué de estas respuestas negativas. Para varios jóvenes como Pedro, expresar que no le gustaba el quechua estaba más vinculado con la falta de oportunidades significativas de acercarse al idioma - desde el hogar y la escuela- que a un completo desinterés por este.

Los jóvenes también criticaban las condiciones materiales y pedagógicas bajo las cuales se realizaba el curso y solían contrastar las diferencias que observaban entre asignaturas:

... en inglés es súper divertido porque nos dicen "esto haz", canciones, en todo así; y, en cambio, en quechua... es como que pasas a una tienda encuentras todo y aquí no encuentras nada... No hay casi muchos recursos como para poder aprender bien y, en inglés, hay todo... Les traen computadoras ... Se supone que todos deberíamos aprender como el inglés (Alonso, E, 2017).

Desde el primer año del curso, los jóvenes eran conscientes del diferente peso simbólico del curso, que se reflejaba en el tiempo limitado, la falta (o poca pertinencia) de materiales y la calidad de enseñanza. Observé también, en repetidas ocasiones, cuestionamientos hacia sus profesores, a quienes les pedían más horas de enseñanza ("una hora se pasa volando, o sea, no aprendes nada", "con 45 minutos a la semana te juro que no es suficiente") o avanzar más como en otros cursos, o les disputaban el tener que pagar por materiales. Si bien los alumnos objetaban la corta duración del curso, el tema de fondo era repensar el enfoque de enseñanza. En conversación con estudiantes de quinto de secundaria, me contaron que estarían de acuerdo con llevar hasta tres horas de quechua a la semana - aunque dependería del profesor, puesto que podría ser tres horas de lo mismo-. 
En respuesta a la forma en que les gustaría aprender el quechua, los estudiantes señalaron: "hablando, de forma dinámica, videos, de todas formas, dialogando/hablando y escribiendo" (ES, 2016). Además, indicaron que querían profesores que les hablaran constantemente en la lengua, y estrategias y actividades que distaban de las prácticas educativas dominantes. El tipo de relaciones que tenían con sus docentes también tomaba importancia al evaluar el curso. Aunque algunos jóvenes cuestionaban las habilidades lingüísticas de sus docentes, lo que más criticaban eran actitudes autoritarias o inflexibles, que no respondían a sus demandas de aprendizaje o conocimientos previos.

\section{Conclusiones y reflexiones finales}

En este artículo, he dado a conocer que los repertorios comunicativos de los jóvenes no son homogéneos ni fijos, sino que se expanden y contraen a lo largo de sus vidas. Asimismo, he explicado que los usos y significados de estos repertorios y trayectorias están ligados a relaciones sociales; posicionamientos identitarios; trayectorias racializadas; ideologías lingüísticas; y presiones institucionales, incluidas aquellas ejercidas por las escuelas. Los jóvenes, además, enfrentan distintas fuerzas - como acceso desigual a oportunidades de aprendizaje de quechua, discriminación y jerarquías lingüísticas, e ideologías que cuestionan e invisibilizan sus habilidades e interés por el quechua-. A veces, reproducen o cuestionan estas fuerzas, pero, principalmente, negocian con ellas cotidianamente y dentro de sus escuelas.

En relación con las identidades juveniles, se observó que las formas en que los jóvenes se entienden a sí mismos como aprendices y/o hablantes del quechua se caracterizan tanto por su complejidad como por su ambivalencia. Los jóvenes asumían estos posicionamientos identitarios, en ocasiones, con certeza; y, otras veces, de manera más efímera y dinámica. Estos posicionamientos identitarios se situaban en contextos en los que se promovían políticas lingüísticas escolares para el quechua, donde esta lengua era parte de algunas interacciones familiares $y$, a la vez, donde se reproducía la desigualdad y la discriminación contra sus hablantes. A pesar de esta ambivalencia, la mayoría de los jóvenes expresaba interés por continuar siendo o por convertirse en hablantes de quechua, un interés que debería ser valorado.

Para finalizar, ¿qué implicancias ofrecen estos hallazgos para la enseñanza de lenguas originarias y la construcción de una EIB urbana? Si bien las escuelas estudiadas no implementaban una EIB urbana ni se identificaban con esta propuesta, considero que las características de estas escuelas - en términos de prácticas educativas, población estudiantil y docente- guardan relación con los contextos donde se busca implementar este modelo educativo.

En primer lugar, las escuelas y los docentes necesitan contar con recursos y estrategias para conocer los repertorios comunicativos de sus estudiantes. Aunque los actuales lineamientos proponen realizar una caracterización socio y psicolingüística (Minedu, 2018), debemos asegurar que estos procesos 
diagnósticos incluyan no solo las valoraciones hacia las lenguas, sino también las valoraciones e ideologías sobre los hablantes, y que trasciendan la evaluación del dominio en la lengua de los estudiantes. Asumir una postura de (re) conocimiento frente al bilingüismo juvenil, en primera instancia, implicaría conocer las prácticas sociales en que los jóvenes participan desde distintas identidades y a través de diversas habilidades lingüísticas (orales/escritas, productivas/receptivas), sus conocimientos previos sobre y del lenguaje, las oportunidades y la falta de oportunidades para desarrollar su bilingüismo, los puntos de quiebre en sus historias de vida, y sus preocupaciones y deseos en relación con su identificación y uso de lenguas originarias. Al realizar esta tarea, como educadores, debemos cuestionar nuestros prejuicios o supuestos sobre el bilingüismo, el uso de lenguas y la transmisión intergeneracional, de modo que podamos conocer estos repertorios comunicativos.

Reconocer el bilingüismo juvenil supone, en segunda instancia, involucrar a los jóvenes en el desarrollo de propuestas de educación de lenguas originarias ${ }^{16}$. Me refiero a propuestas en plural, debido a que la diversidad del bilingüismo e identidad juvenil presente en estos contextos no se presta a modelos o metodologías únicas ${ }^{17}$. Como ha demostrado el estudio, muchas de las prácticas educativas existentes alejan a los jóvenes del quechua. Así, resalta la urgencia de dialogar con la juventud y escuchar cómo, para qué y por qué quieren aprender sus lenguas originarias. Estos diálogos brindarían pautas para planificar oportunidades de aprendizaje que permitan ampliar sus repertorios comunicativos. Algunos puntos importantes a considerar incluyen la importancia de la oralidad en quechua identificada por los jóvenes, la necesidad de crear oportunidades para que esta lengua sea utilizada cotidianamente en la construcción de una convivencia escolar entre docentes y compañeros, y una apropiación significativa de la escritura.

Sería importante incluir a sus familiares en este proceso, y comenzar a tejer puentes entre las prácticas educativas escolarizadas y comunitarias en pro de la revalorización y el uso de las lenguas originarias, además de conocer los intereses o dificultades que experimentan las familias en esta labor. Estas alianzas podrían movilizar a actores comunitarios como aliados de una EIB urbana, y también ayudarían a visibilizar la vigencia de prácticas lingüísticas quechuas comunitarias y familiares, en gran parte ausentes en las aulas. Asimismo, estas acciones pueden promover identificaciones positivas locales sobre lo que significa reconocerse como un hablante de la lengua, modelos de persona que no circulaban muy frecuente o abiertamente en las aulas. Asumir la enseñanza de lenguas originarias como un proceso en construcción, además,

16. Reconozco que una EIB urbana también debe considerar una propuesta de enseñanza en lenguas originarias, un tema fuera del alcance del presente artículo.

17. La propuesta del Minedu (2018) indica que la EIB urbana debe utilizar una metodología de segundas lenguas (p. 19), lo cual no refleja pertinentemente el bilingüismo de toda esta población ni sus necesidades. 
abre oportunidades para promover prácticas de reflexión y evaluación colaborativas entre docentes, estudiantes y otros actores educativos.

En tercera instancia, una EIB urbana no puede limitarse a la enseñanza de la lengua originaria como un código abstracto, sino que debe preocuparse por el significado simbólico y material de estas lenguas para sus hablantes y aprendices. Resulta necesario que la escuela sea un espacio donde se identifiquen y cuestionen representaciones negativas sobre los hablantes de lenguas originarias, principalmente, aquellas que se reproducen — muchas veces, de manera desapercibida - dentro de las mismas. Este cuestionamiento formaría parte de la apuesta por una interculturalidad crítica (Walsh, 2012), la cual toma como punto de partida el cuestionamiento de los patrones de racialización de los grupos subalternos y las relaciones de poder a través de las cuales se construyen y jerarquizan las diferencias. Una EIB urbana debería cuestionarse cómo estas diferencias se construyen a través del lenguaje y en relación con el lenguaje, y la forma en que dichas diferencias no impactan a todos los jóvenes de las mismas maneras. Siguiendo este enfoque crítico, es importante que, desde la escuela, junto con los estudiantes, se cuestionen las asociaciones ideológicas que sostienen y naturalizan visiones, prácticas, e instituciones discriminatorias y racistas que atentan contra sus experiencias como hablantes, aprendices $\mathrm{y}$ - sobre todo-como individuos.

La cuarta implicancia se vincula con el rol de la enseñanza de lenguas originarias en promover una afirmación identitaria cultural de los jóvenes como miembros de pueblos originarios (Minedu, 2018, p. 17). Si consideramos que las identidades se construyen en relación con los otros y a través de la interacción, no podemos asumir a los jóvenes como receptores de identidades innatas o esencialistas. Más bien, el entendimiento de la identidad compartido en este artículo nos conduce hacia una visión de la escuela EIB como un espacio donde los jóvenes participen en la creación de identidades étnicas o culturales diversas. El investigador indígena myaamia Wesley Leonard (2012) sugiere que los proyectos de reclamación de lenguas indígenas pueden ser entendidos como esfuerzos liderados por una comunidad para reivindicar su derecho a hablar una lengua, y a establecer objetivos relacionados a las necesidades y perspectivas del colectivo, las cuales reflejarían la diversidad contemporánea de este grupo (p. 359). Josep Cru (2021) analiza las prácticas de rap en lenguas originarias en distintos contextos latinoamericanos para enfatizar que los jóvenes pueden asumir su competencia comunicativa en lenguas originarias como parte de procesos de identificación cultural desde diversas posturas - socioculturales, espirituales o políticas-. Considerando el dinamismo y la heterogeneidad del bilingüismo e identidad juvenil estudiados, y tomando en cuenta estos aportes, la EIB urbana podría pensarse como un proyecto desde el cual los jóvenes puedan reflexionar en torno a su participación en la construcción de identidades indígenas que abarquen vivencias a lo largo de espacios urbanos y rurales, a través del quechua y junto a otras lenguas, y enraizadas en conocimientos tradicionales y contemporáneos. 
Este acercamiento a la afirmación identitaria, además, puede apoyar a transformar representaciones del quechua y de sus hablantes - las que han sido asociadas a un pasado histórico y/o mítico, o a una posición de inferioridadproponiendo nuevas representaciones en las que los protagonistas también sean los quechuas contemporáneos, y que reconozcan sus diversas vivencias, conocimientos, cosmovisiones, espiritualidades y luchas políticas. Del mismo modo, no debemos esperar o exigir que esta construcción identitaria sea homogénea. Haríamos bien en considerar la diversidad de identidades quechuas en configuración. Es posible, por ejemplo, que estas identidades, vayan de la mano con o hasta se vean ensombrecidas por otras identidades - como lo que significa venir de un territorio o comunidad en particular, el tipo y grado de oportunidades económicas a las que se tiene acceso, identidades de género, posturas generacionales y otras identidades étnicas (indígenas y no-indígenas) con las que los jóvenes se identifiquen-.

La construcción de la enseñanza de lenguas originarias en secundarias urbanas no se encuentra libre de desafíos. Esta tarea abarca tan solo una parte de los distintos componentes que constituyen una EIB urbana. Sin embargo, reconocer el bilingüismo y su vínculo con la identidad juvenil desde una perspectiva sociolingüística crítica y etnográfica ofrece aportes para construir una EIB más cercana a la diversidad de experiencias, dilemas, y sueños de aprendizaje y de vida de los jóvenes.

\section{Agradecimientos}

Tukuy sonqoywanmi llapan Urubamba yachay wasikunapi reqsisqaykunaman, wayna sipaskunaman, familiankunamanpas, yachachiqninkunamanpas añaychani ${ }^{18}$. Agradezco también a Nancy Hornberger y Virginia Zavala por su mentoría y ánimos en la realización de esta investigación. El estudio contó con el apoyo financiero de la Inter-American Foundation, el Programa FulbrightHays y la American Educational Research Association. A mi grupo de escritura, Norbella, Aldo y Sofía, gracias por su lectura generosa. Asimismo, valoro los comentarios de mis revisores, los cuales ayudaron a enriquecer este artículo. Todas las faltas u omisiones son mías.

18. Agradezco profundamente a todos los jóvenes y docentes que participaron en este estudio y me recibieron en sus aulas, escuelas y hogares. 


\section{Referencias}

Agha, A. (2007). Language and Social Relations. Cambridge University Press. Andrade, L. (2019). Diez noticias sobre el quechua en el último censo peruano. Letras (Lima), 90(132), 41-70. https://doi.org/10.30920/letras.90.132.2

Barton, D. y Hamilton, M. (2004). La literacidad entendida como práctica social. En V. Zavala, M. Niño-Murcia, P. Ames (Eds.), Escritura y sociedad. Nuevas perspectivas teóricas y etnográficas (pp. 109-140). Lima, Perú: Red para el Desarrollo de las Ciencias Sociales en el Perú.

Blackledge, A. y Creese, A. (2010). Multilingualism: A Critical Perspective. Continuum International Publishing Group.

Blommaert, J. (2009). Ethnography and democracy: Hymes's political theory of language. Text \& Talk, 29(3), 257-276.

Blommaert, J. y Backus, A. (2013). Repertoires Revisited: "Knowing Language" in Superdiversity. Working Papers in Urban Language and Literacies, 67, $1-26$.

Bucholtz, M. y Hall, K. (2005). Identity and Interaction: A Sociocultural Linguistic Approach. Discourse Studies, 7(4-5), 1-30.

Córdova, L. (2015). Buscando nuevas generaciones de hablantes: procesos ambivalentes en la revitalización de lenguas indígenas del Sur de México. En: J. Cru (Ed.), The Role of Youth in Language Revitalization (pp.76-86). Linguapax.

Coronel-Molina, S. M. (2015). Language Ideology, Policy and Planning in Peru. Multilingual Matters.

Cru, J. (2021). Rap en lenguas originarias: de la recreación artística a la denuncia sociopolítica. Ichan Tecolotl, 345. https://ichan.ciesas.edu.mx/ rap-en-lenguas-originarias-de-la-recreacion-artistica-a-la-denunciasociopolitica

Erickson, F. (1986). Qualitative Methods in Research on Teaching. En: M. C. Wittrock (Ed.), Handbook of Research on Teaching (3ra ed., pp. 119-161). MacMillan.

García, O. (2009). Bilingual Education in the 21st Century: A Global Perspective. John Wiley \& Sons.

Guerrettaz, A. M. (2020). ¿A quiénes les pertenece el maya yucateco? Revitalización y políticas lingüísticas en Yucatán, México. En: M. NiñoMurcia, V. Zavala y S. De los Heros (Eds.), Hacia una sociolingüística crítica. Desarrollos y debates (pp. 267-302). Instituto de Estudios Peruanos.

Hecht, A. (2018). Maestros/as Indígenas en contextos de desplazamiento lingüístico: desafíos y dilemas contemporáneos. Cuadernos del Instituto Nacional de Antropología y Pensamiento Latinoamericano, 26(2), 87-100. 
Heller, M. (2020). Hacia un enfoque social del bilingüismo. En: M. NiñoMurcia, V. Zavala y S. De los Heros (Eds.), Hacia una sociolingüística crítica. Desarrollos y debates (pp.115-147). Instituto de Estudios Peruanos.

Hornberger, N. (1989). Haku yachaywasiman: la educación bilingüe y el futuro del quechua en Puno. Programa de Educación Bilingüe de Puno.

Hornberger, N. H. (2014). "Until I Became a Professional, I Was Not, Consciously, Indigenous": One Intercultural Bilingual Educator's Trajectory in Indigenous Language Revitalization. Journal of Language, Identity \& Education, 13(4), 283- 299.

Huayhua, M. (2017). Interacción social y racismo en el transporte público puruano. En V. Zavala y M. Back (Eds.), Racismo y Lenguaje (pp. 83-114). Fondo Editorial PUCP.

Hymes, D. H. (1972). Models of the Interaction of Language and Social Life. En: J. J. Gumperz y D. Hymes (Eds.), Directions in Sociolinguistics: The Ethnography of Communication (pp. 35-71). New York, NY: Holt, Rinehart and Winston.

Instituto Nacional de Estadística e Informática [INEI] (2017). Perú: Resultados Definitivos de los Censos Nacionales 2017. XII de Población, VII de Vivienda y III de Comunidades Indígenas. INEI.

Kvietok, F. (2019). Youth bilingualism, identity and Quechua language planning and policy in the urban Peruvian Andes. PhD dissertation, University of Pennsylvania.

. (2021). "Llegando a secundaria les ha dado amnesia...ya no quieren hablar": Indigenous Speakerhood Socialization and The Creation of Language Deniers in Quechua Education. Linguistics and Education, 61. https://doi.org/10.1016/j.linged.2020.100888

Leonard, W. Y. (2012). Reframing Language Reclamation Programmes For Everybody's Empowerment. Gender and Language, 6(2). https://doi. org/10.1558/genl.v6i2.339

López, L. E. Küper, W. (1999). La educación intercultural bilingüe en América Latina: balance y perspectivas. La Revista Iberoamericana de Educación, 20, $17-85$.

Mamani, C. (2019). Desarrollo de capacidades interculturales a través de la incorporación del diálogo de saberes con niños y niñas del sexto grado de una escuela primaria EIB de la región del Cusco. Tesis de pregrado, Universidad Peruana Cayetano Heredia. https://hdl.handle.net/20.500.12866/8558

Martin-Jones, M. (2007). Bilingualism, education and the regulation of access to language resources. En: M. Heller (ed.), Bilingualism: A Social Approach (pp. 161-182). Palgrave Macmillan.

Mendoza, Z. S. (2008). Creating Our Own: Folklore, Performance, and Identity in Cuzco, Peru. Duke University Press. 
McCarty, T. L., Romero-Little, M. E., Warhol, L. y Zepeda, O. (2009). Indigenous Youth as Language Policy Makers. Journal of Language, Identity, and Education, 8(5), 291-306.

Miles, M. B., Huberman, A. M. y Saldaña, J. (2014). Qualitative Data Analysis: A Methods Sourcebook (3ra ed.). Thousand Oaks, CA: SAGE Publications.

Resolución Ministerial 519-2018-MINEDU. 20 de setiembre de 2018.

Niño-Murcia, M., Zavala, V., y Delos Heros, S. (2020). Hacia una sociolingüística crítica. Desarrollos y debates. IEP.

Paris, D. y Winn, M. T. (Eds.) (2014). Humanizing Research: Decolonizing Qualitative Inquiry with Youth and Communities. SAGE Publications.

Sichra, I. (2006). Enseñanza de lengua indígena e interculturalidad: ¿entre la realidad y el deseo? PROEIB Andes.

Sumida Huaman, E. (2014). "You're Trying Hard, But It's Still Going To Die": Indigenous Youth and Language Tensions in Peru and the United States. Anthropology and Education Quarterly, 45(1), 71-86.

Unamuno, V. (2013). ¿De qué hablamos cuando hablamos de bilingüismo en EIB? Notas desde el Chaco. En: M. Censabella y C. Messineo (Eds), Lenguas indígenas de América del Sur II. Morfosintaxis y contacto de lenguas (pp. 171-188). Editorial FFyL-UNCuyo y SAL. http://www.ffyl. uncu.edu.ar/spip.php?article3977

. (2015). Los hacedores de la EIB: un acercamiento a las políticas lingüístico-educativas relativas a la educación indígena desde las aulas bilingües del Chaco. Education Policy Analysis Archives, 23(0), 101. https:// doi.org/10.14507/epaa.v23.2061

Valdés, G. (2015). Latin@s and the Intergenerational Continuity of Spanish: The Challenges of Curricularizing Language. International Multilingual Research Journal, 9(4), 253-273.

Walsh, C. (2012). Interculturalidad crítica y (de)colonialidad. Ensayos desde Abya Yala. Ediciones Abya Yala.

Wolcott, H. F. (1987). On Ethnographic Intent. En: G. Spindler y L. Spindler (Eds.), Interpretive Ethnography of Education: At Home and Abroad (pp. 37-56). Lawrence Erlbaum Associates.

Wortham, S. (2005). Socialization Beyond the Speech Event. Journal of Linguistic Anthropology, 15(1), 95-112.

Zavala, V. y Córdova, G. (2010). Decir y callar: Lenguaje, equidad y poder en la Universidad peruana. Fondo Editorial PUCP.

Zavala, V., Mujica, L., Córdova, G. y Ardito, W. (Eds.). (2014). Qichwasimirayku: Batallas por el quechua. Fondo Editorial PUCP. 